\title{
MANUFACTURE OF TOMATOES HALVING PROTOTYPE FOR NATURAL DRYING PROCESS
}

\author{
Wael. A. Mahmoud ${ }^{1 \& *}$ \\ ${ }^{1}$ Assist. Prof., Fac. of Ag. Eng., Al-Azhar U., Assiut Branch, Egypt. \\ *E-mail: waelshaban.50@azhar.edu.eg
}

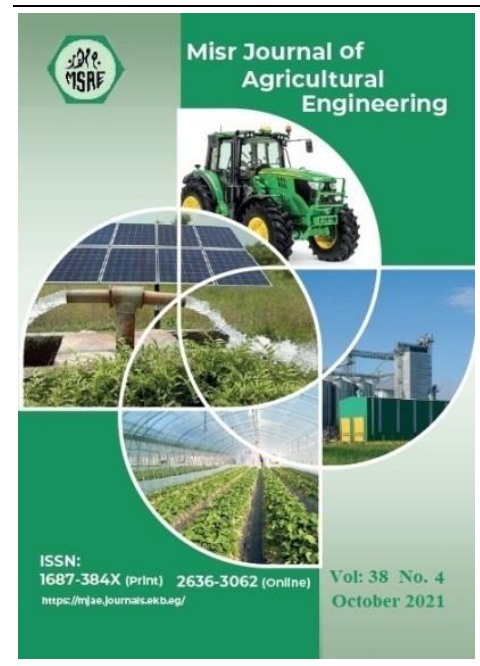

(ㄱ Misr J. Ag. Eng. (MJAE)

\section{Keywords:}

Tomatoes sun drying; Cutting machine; Machine productivity; Cutting efficiency

\begin{abstract}
Tomatoes are an important component of the human diet but possess a very short post-harvest shelf-life which makes them highly perishable. This causes a problem in the transportation and handling of tomato fruits. The open natural sun drying of tomatoes in Upper Egypt is the best solution to this problem. Most processes of halving cutting tomatoes are manual, this process is a cumbersome, time-consuming, and labor-intensive job. So, this research aims to develop, fabricated, and evaluated the performance of halving cutting tomatoes prototype made with local materials, suitable for three cultivars (Nesma, Masa, and 2020) costumed for sun drying. The major components of the machine include the frame, the conveyor belt, cutting sow blade (smooth edge, inclined and straight teeth), electric motor, and power transmission system. The factors for evaluating performance of prototype included estimating the appropriate feeding rate, percentage of damage rate, cutting efficiency and productivity and calculating initial operating costs compared to manual halving costs. The results of the prototype performance evaluation showed that increasing the linear speed of the conveyor belt leads to decrease in productivity while decrease in cutting efficiency of the fruits. The best average productivity was achieved of highest cutting efficiency and least damage percentage at lowest linear speed of conveyor for three cultivars. The results also showed lower operating costs of the prototype at lowest linear speed of conveyor belt compared to manual cutting. Recommended that developing of this prototype to clean, dry and grade the fruits before halving.
\end{abstract}

\section{INTRODUCTION}

$\mathrm{T}$

The production of dried tomatoes is proportional to the conditions of Egypt's weather in winter (Luxor and Aswan) and in summer (Northern Egypt). The production period (sun drying) in Egypt can reach 8 months per year, which is consider longest period of production. The preferred varieties for drying are often the solid varieties at harvest and fully colored, which contain a large content of total solids. Most tomato drying projects lack the mechanization of slicing, the slicing is still done manually by women laborers, and lacks full information about the physical properties of the preferred tomato varieties for drying. Egypt occupies the fifth center globally in the production of tomatoes, with an annual production 
volume of close to 7 million tons (FAO, 2020), but the tomato crop is exposed to loss in the harvesting and production stages and during retail and wholesale operations, as well as a significant loss in the level of product quality. Therefore, the sun drying of tomatoes is one of the technical solutions to reduce the losses in this strategic crop (Bahaa, 2020). The shelf life of tomatoes is relatively short postharvest life and during fruit ripening, many qualityaffecting processes take place (Hoeberichts et al., 2002). Cutting tomatoes before open sun drying is very essential as it aids in fast and effective drying. Slicing of tomato opens the capillary tubes through which moisture flows to the surface of sliced tomatoes where vaporization of the moisture takes place and then being carried away by air flows during drying (Kamaldeen et al., 2016). In the drying of fruits and vegetables, the vegetables and fruits must be sliced into smaller pieces to facilitate heat transfer and removal of moisture from the pieces (Agbetoye and Balogun, 2009). The physical properties of tomato are important to design the equipment for processing, transportation, sorting, separation, and storing. Designing such equipment without consideration of these properties may yield poor results. Therefore, the determination and consideration of these properties have an important role (Taheri et al., 2009). Tomatoes are best dried when sliced and slicing of tomatoes had been considered difficult operation as it is usually done manually. The manual means of slicing tomatoes is energy and time consuming and of course prone to injury when not done carefully (Kamaldeen and Awagu, 2013). Slicing operation is achieved by cutting, which involves moving, pushing, or forcing a thin sharp blade or knife through the materials resulting in minimum rupture and deformation of the materials (Raji and Igbeka, 1994).

A tomato manual slicing machine was developed and designed by (Kamaldeen and Awagu, op. cit.)؛ the machine operates on the principle of shearing force of moving knife against tomatoes placed on a stationary part of the machine. It was designed to cut tomatoes in $2 \mathrm{~cm}$ thickness. The capacity of the machine was $540.09 \mathrm{~g}$ per minute $(32.41 \mathrm{~kg} / \mathrm{h})$ and its performance efficiency was $70 \%$. (Kamaldeen et al., op. cit.) modified an existing manually operated tomato slices and compared the performance of the two machines. The machines worked basically on the same principle of shearing force of moving knife against tomatoes placed on a stationary part of the machine. Improvements in the new machine were in the form of the use of metals as the machine components instead of wood, improved cutting blades, and provision of collection unit. The slicing efficiency and output capacity of the newly developed slicer were $90.10 \%$ and $3.79 \mathrm{~kg} / \mathrm{h}$ respectively. Shittu et al., (2017) mention that one major limitation of the available slicing machines is low output capacity that cannot meet the needs of ever-growing dried tomato industries. The low output capacity is due to low cutting speed and one-by-one, or batch feeding system applied. Designed and fabricated machine to slice tomatoes into a recommended size of $20 \mathrm{~mm}$ thick for fast drying. The slicer consists mainly of a feeding unit, cutting compartment, collection unit, power section, and tool frame. Tomato fruits fed through the feeding unit go down to the cutting compartment by gravitational force and the reciprocating motion of slicing knives cut the fruits by shearing action, in the design of the tomato slicer, the physical properties of the UC82B tomato cultivar were considered. Results of the performance evaluation showed that the machine has an output capacity of $468 \mathrm{~kg} / \mathrm{h}$., percentage loss of $28.40 \%$, and slicing efficiency of $60.34 \%$. 
After a careful empirical study of the traditional method of cutting tomatoes under natural drying, it was noted that it is slow, laborious, expensive, and requires more manual labor, as well as injuries to laborers hands. So, the current research aims to the development of a prototype to cut the fruits of tomatoes into two identical halves.

\section{MATERIALS AND METHODS}

The manufacturing feature of the machine includes three major characteristics: a simple design, ease of use and its parts are locally available materials in addition to low costs manufacture and ease of fabrication.

\section{General consideration of cutting prototype:}

Some parts of the cutting machine prototype were designed based on the following consideration:

- The dimensions of the transmission mechanical parts and the cutting unit are determined according to the physical properties of the three most important tomato cultivars are specified for natural sun dryings, such as commercial cultivars Nesma, Masa, and 2020 (Solanum Lycopersicum Mill.) according to (Mahmoud et al., N. d.).

- Due to the nature of tomato fruit that is inherently soft, a device for cutting is expected to be thin and sharp. It must be able to penetrate the fruits and the construction materials must not contaminate the fruits and not be corroded when in contact with water.

- Considering the recommendations of the Food and Agricultural Organization on how to cut tomatoes for the purpose of open sun drying (Bahaa, 2020) are following:

a. Tomato fruits are cut longitudinally through the central axis into two halves (the outer peel is left in the cutting area).

b. The cutting is done using a sharp knife so that the fruit tissues are not disturbed during cutting and places for collecting water are formed, which leads to the growth of fungi and the occurrence of molds.

c. To be completely in the middle so that it is easy to dry all the fruits at the same rate and at the same time.

d. Sorting out any infected fruits that are not suitable for drying before cutting.

e. It is preferable to gradient before cutting to obtain homogeneity in the drying process.

Some parts of the cutting prototype were designed based on some consideration such as dimensions of the transmission mechanical parts and the cutting unit are determined according to the physical properties of the three most important tomato cultivars intended for open sun drying, such as Nesma, Masa, and 2020 commercial cultivars of tomato according to (Mahmoud et al., op. cit.), due to the nature of tomato fruit that is inherently soft, a device for cutting is expected to be thin and sharp. It must be able to penetrate the fruits and the construction materials must not contaminate the fruits and not be corroded when in contact with water.

\section{Tomato fruits}

Random samples of 100 tomato fruits ware used for each of the specified varieties (Nesma, Massa and 2020) to test the performance of the prototype in cutting tomatoes into identical halves for the purpose of open sun-drying. The fruits were obtained from the tomato sun- 
drying project at Al-Qurna Agricultural Secondary School in Luxor Governorate, Egypt, during February (2021) and kept inside polyethylene bags in a refrigerator at $4{ }^{\circ} \mathrm{C}$ before measurements. The measurements and tests were carried out in the Fac. of Agri. Eng., AlAzhar U., Assiut in the day after the harvest.

\section{III.Components of prototype tomatoes halving machine}

Figures (1) and (2) shows the components of the developed prototype for cutting tomatoes that consists of the following parts:

a. The frame; was fabricated from welded steel, and it was formed with certain dimensions of $400 \mathrm{~mm}$ wide, $1300 \mathrm{~mm}$ length, and $900 \mathrm{~mm}$ height. Two hinges are assembled at the cover of the frame to control the opening and closing, to protect the laborer against the cutting disk.

b. Rubber belt conveyor; moves according to the principle of friction transmission, the prototype contains one conveyor belt. The length of conveyor belt (from the center of two rollers) is $1100 \mathrm{~mm}$ and has a width of $150 \mathrm{~mm}$. The conveyor belt revolves around two steel rollers $100 \mathrm{~mm}$ diameter and width of $160 \mathrm{~mm}$ that are provided with two edges to prevent the belt from swerving. It contains $50 \mathrm{~V}$-shaped cells made of galvanized iron, that are distributed with $25 \mathrm{~mm}$ intervals. this shape of the cell was chosen based on the variation in the volume of tomatoes fruits cultivars and can accommodate small and large fruits. This shape also allows the fruits to be fixed during cutting by the cutting disc. Dimension of V-cell are showing in Figure (3). Tomatoes are placed on the V-cells manually by the operator.

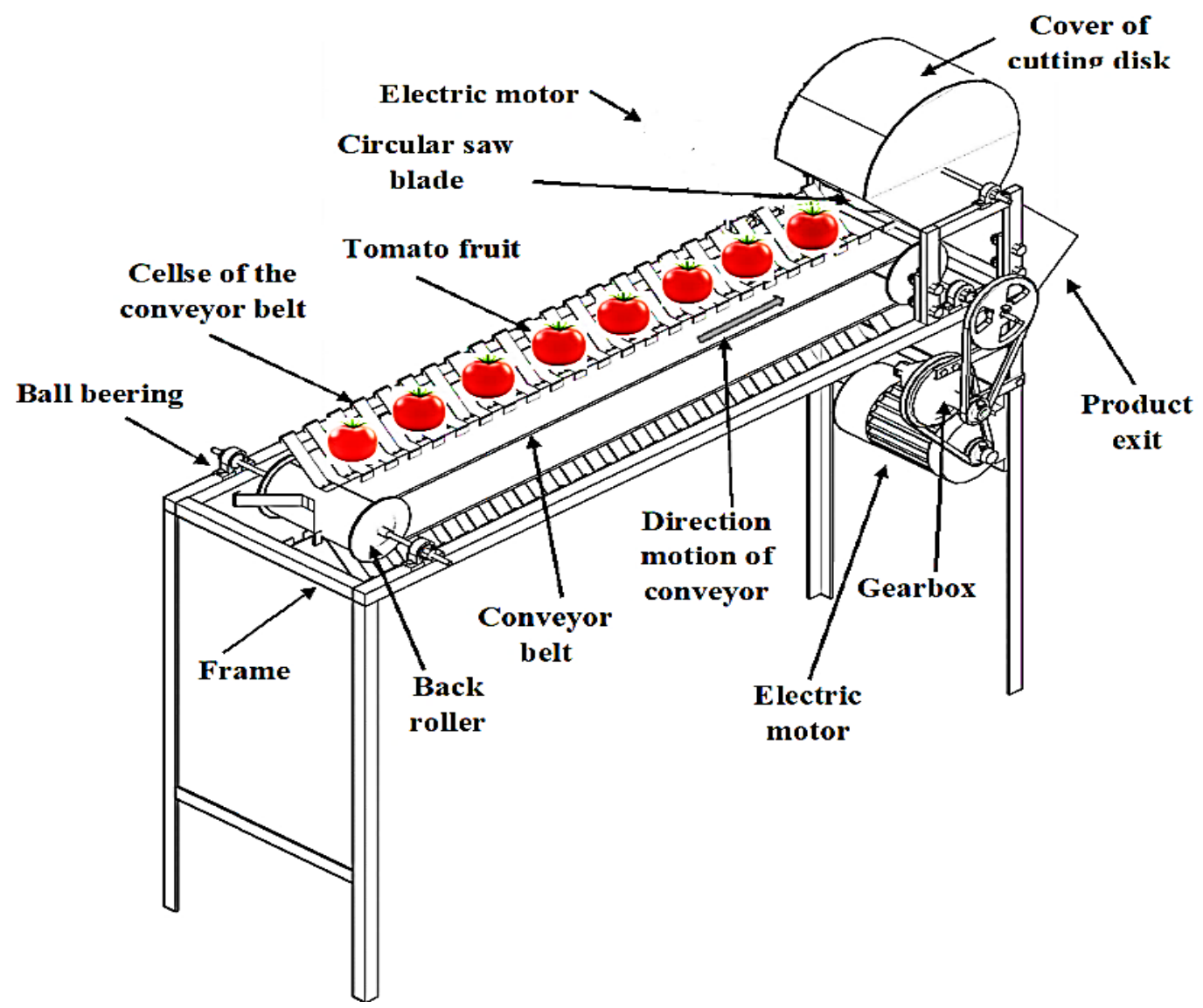

Figure (1): The prototype of tomatoes halving 


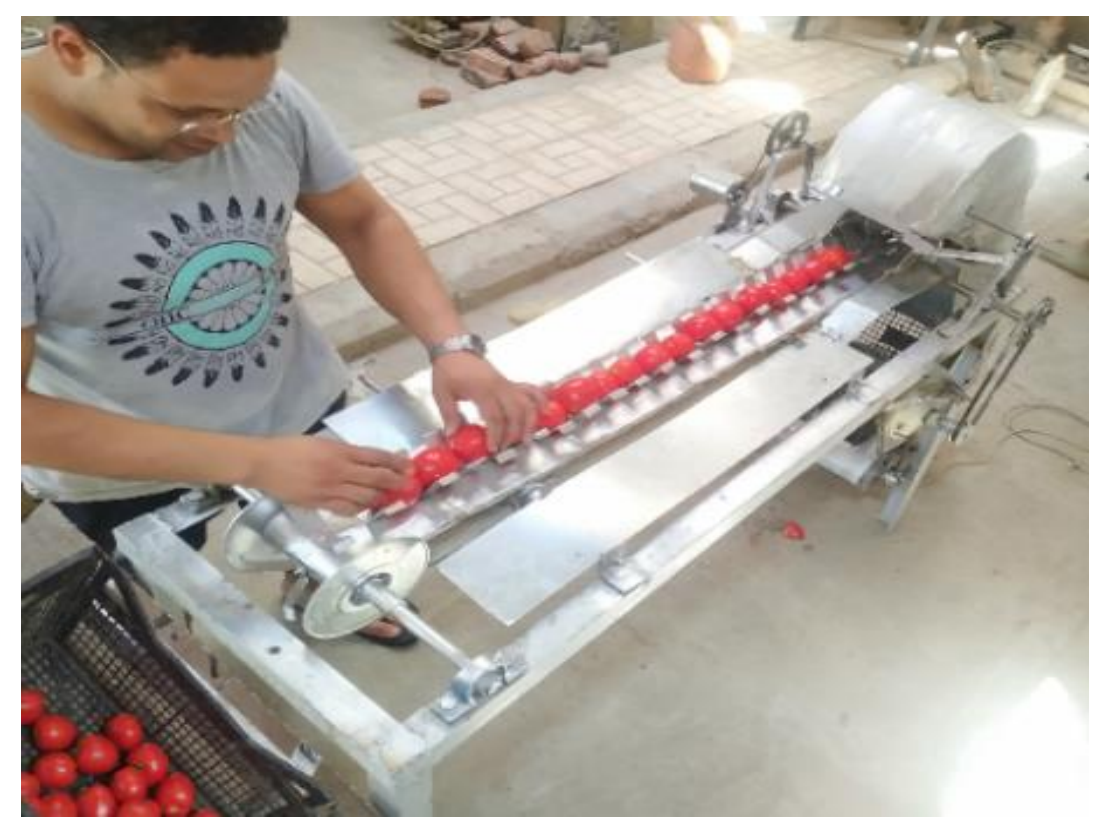

Figure (2): The halving tomatoes during the operating

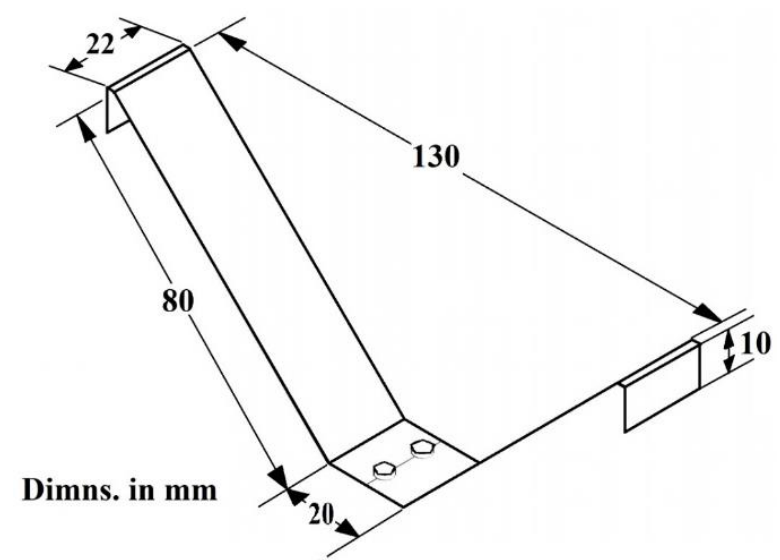

Figure (3): Dimensions of V-cell

The conveyor belt design considerations are based on can bear the appropriate number of tomatoes, considering the largest mass of tomato fruits according to values of the aspect ratio, the fruits of the Nesma and Masa cultivars can be placed on the conveyor belt in a vertical position, while the fruits of the 2020 cultivars are placed in a horizontal position and the width of the V-cells must not be less than the largest diameter of a tomato fruit $87.88 \mathrm{~mm}$ for the Nesma variety according to (Mahmoud et al., op. cit.). Referring to principle mathematical lows and according to (Ananth et al., 2013) the conveyor belt recorded 251.4 $\mathrm{cm}$.

Cutting unit; Three types of Stainless-steel circular saw blades (Smooth, serrated with inclined teeth, and serrated with straight teeth) are used in the cutting unite as shown in figure (4). Figure (5) illustrates the processing of halving tomatoes through the operating of cutting unit. Dimensions of all saw blades are diameters of $22 \mathrm{~mm}$ and thickness of $0.5 \mathrm{~mm}$ and 80 teeth. The clearance between saw blades and conveyor is $3 \mathrm{~mm}$. The saw blade relates to the power transmission shaft that is based on a pair of bearings and rotating with $300 \mathrm{rpm}$, and the motion is transmitted by the transmission system of the electric motor as shown in figure (6). 
Electric motor; (Model No.: Y2, Brand: TOPS Motor) 280 Watt and $1200 \mathrm{rpm}$ was used to rotate the rollers to moving the conveyor belt forward and rotating the saw blade knife.

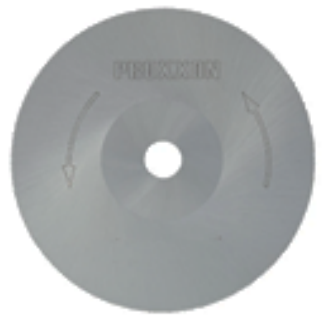

Smooth

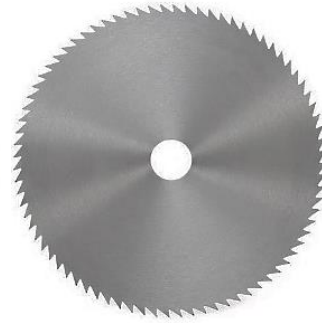

Inclined teeth

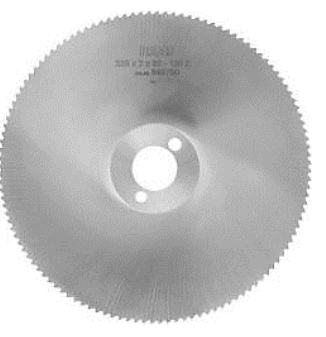

Straight teeth

Figure (4): Types of Stainless-steel circular saw blades
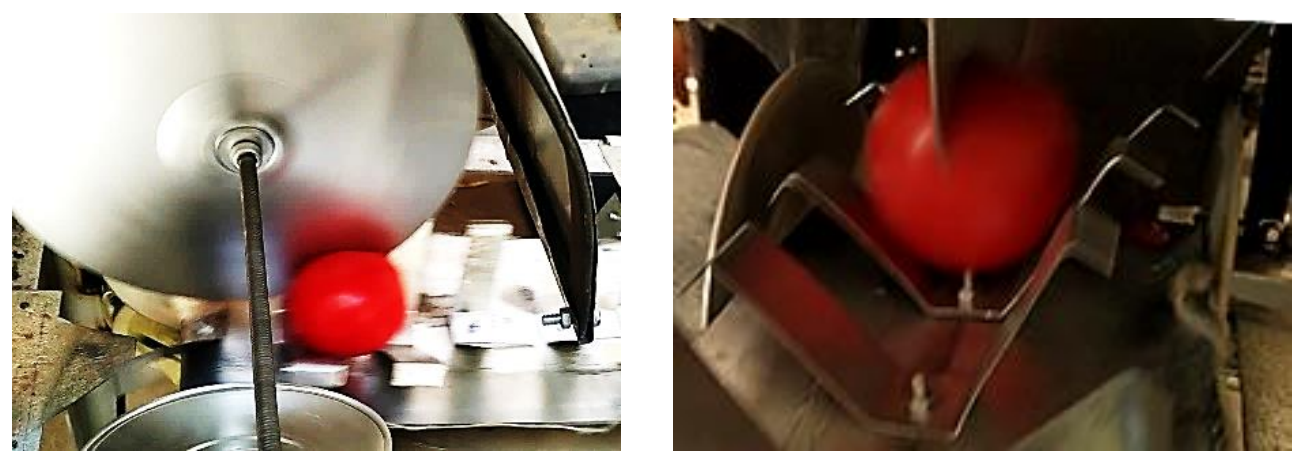

Figure (5): Processing of dividing tomatoes through operating of cutting unit

Power transmission system; is transmitted power from electric motor to conveyor by set of pulleys and gearbox (with speed ratio of 4:1). Figure (6) shows the schematic power transmission system of the prototype, diameters of pulleys and teeth of gears. The movement is transmitted from the motor to saw blade (7) via of transmission group from (1) to (6), and it transmitted from the motor to driven roller of the conveyor belt (13) via of transmission group from (8) to (12). By using diameters 5, 9 and $14 \mathrm{~cm}$ of pulley (11) can be obtained of linear speeds $0.164,0.294$ to $0.458 \mathrm{~m} / \mathrm{s}$ of conveyor.

The power requirement was calculated as follow; The following values were used during the calculation of power requirement, maximum mass of fruit was 295 grams for the Nesma cultivar (Mahmoud et al., op. cit.), maximum conveyor speed was $0.458 \mathrm{~m} / \mathrm{s}$, total conveyor weight $=7.7 \mathrm{~kg}$, and rotation speed of sow blade disk was $300 \mathrm{rpm}$, required power recorded 77.85 Watt.

Performance parameters; supposed to be estimated within the current research are:

1. Three tomatoes cultivars Nesma, Masa, and 2020.

2. Liner speeds of the conveyor belt $0.164,0.294$ to $0.458 \mathrm{~m} / \mathrm{s}$.

3. Type of circular saw blades smooth, inclined teeth and straight teeth.

4. Compared productivity and production costs between cutting manual and mechanical.

Each experiment was repeated three times to possibility measured effect of linear speed of conveyor belt on the following:

- Feeding rate $(\mathbf{F r}, \mathbf{k g} / \mathbf{h})$; is an indicator of machine productivity per unit time. The appropriate feeding rate depends on the performance of labor and linear speed of the conveyor belt. Before processing the machine evaluation performance tests, the labor was trained to feed of prototype at three linear speeds $(0.164,0.294$ to $0.458 \mathrm{~m} / \mathrm{s})$ of the belt to obtain the 
appropriate feeding rate. Recorded as the total mass of fruits that can be fed by the labor per the unit time.

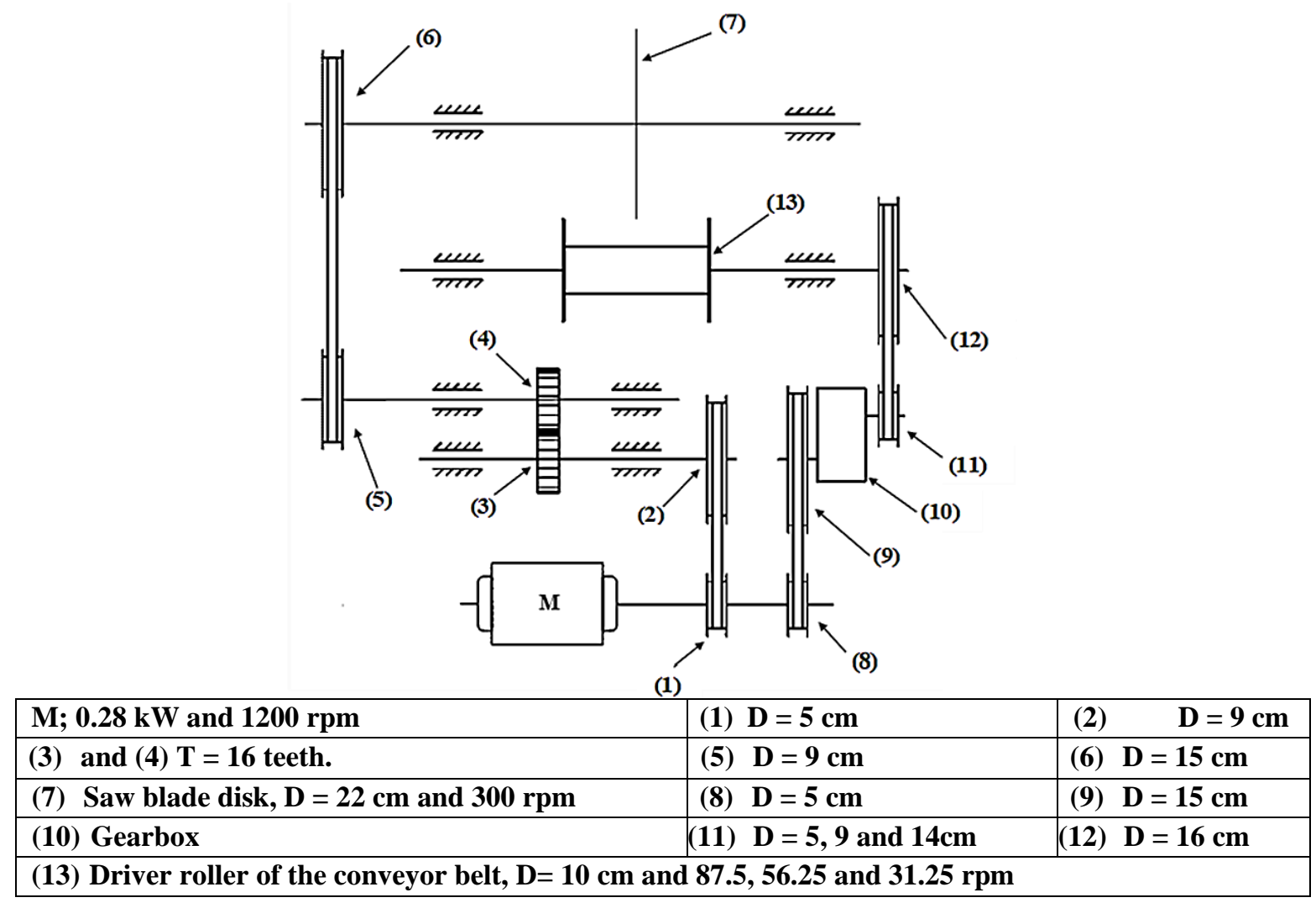

Figure (6): Schematic power transmission system of prototype

- Percentage of the damage (\%DF); it is cutting side or away from their axis, were collected and the rest of their parts and was evaluated using equation by (Agbetoye and Balogun, 2009):

$$
\% \mathrm{D}_{\mathrm{F}}=\mathrm{m}_{\mathrm{d}} / \mathrm{m}_{\mathrm{c}} \times 100
$$

Where; $\mathrm{D}_{F}=$ percentage damage of the fruits $(\%) ; \mathrm{m}_{\mathrm{d}}=$ mass of the damage fruit $(\mathrm{kg})$ and $\mathrm{m}_{\mathrm{C}}$ $=$ total mass of the cutting fruits $(\mathrm{kg})$.

- Cutting efficiency (nc, \%); means the amount of total mass of fruits that are halving into two halves through the vertical axis by the cutting unit per the total mass of the fruits are feeding by labor. The following equation was used to estimate the cutting efficiency according to (Agbetoye and Balogun, 2009):

$$
\eta_{C}=\mathrm{m}_{\mathrm{c}}-\mathrm{m}_{\mathrm{d}} / \mathrm{m}_{\mathrm{c}} \times 100
$$

Where; $\eta_{C}=$ cutting efficiency of tomato fruits $(\%)$ and $m_{d}=$ mass of the damage fruit, $\mathrm{kg}$.

- Cutting quality; is visually tested to judge terms guide of Food and Agricultural Organization to cut tomatoes for the purpose of open sun drying which includes according to (Bahaa, op. cit.);

Longitudinally cutting through the central axis into two halves, the outer peel is left in the cutting area from one side and not laceration tissue when cutting area.

- Machine productivity $\left(\mathrm{P}_{\mathrm{c} . \mathrm{m}}\right)$; was determined using the following equation according to (Ozumba et al. 2004): 


$$
\mathrm{P}_{\mathrm{c} . \mathrm{m}}=\mathrm{m}_{\mathrm{c} . \mathrm{m}} / \mathrm{T} \text {. }
$$

Where; $\mathrm{P}_{\mathrm{c}}=$ the output capacity $(\mathrm{Mg} / \mathrm{h})$; and $\mathrm{T}=$ time of taken $(\mathrm{h}) . \mathrm{m}_{\mathrm{c} . \mathrm{m}}=$ total mass of the cutting fruits is dividing into two halves through the vertical axis $(\mathrm{kg})$.

Manually productivity $\left(\mathbf{P}_{\mathbf{c . h}}\right)$; by using sharp cutting knife for one labor, it had determined using the following equation:

$$
\mathrm{P}_{\mathrm{c} . \mathrm{h}}=\mathrm{m}_{\mathrm{c} . \mathrm{h}} / \mathrm{T} \text {. }
$$

Where; $\mathrm{P}_{\mathrm{c} . \mathrm{h}}=$ manually productivity by on labor $(\mathrm{Mg} / \mathrm{h}) ; \mathrm{m}_{\mathrm{c.h}}=$ total mass of the cutting fruits is dividing into two halves through the vertical axis $(\mathrm{kg})$.

Measuring instruments; was digital electrical balance with accuracy of $0.001 \mathrm{~kg}$, digital Vernier-caliper with accuracy of $0.01 \mathrm{~mm}$ and stopwatch.

\section{Cost estimation;}

Depreciation rate; was estimated using the following equation:

$$
\mathrm{D}=\mathrm{P}_{\mathrm{m}}-S / \mathrm{L}_{\mathrm{m}}
$$

Where; $\mathrm{D}=$ Depreciation rate (L.E./year); $\mathrm{Pm}=$ machine purchase price (estimated price = 5000 L.E); $\mathrm{S}=$ salvage price $(\mathrm{L} . \mathrm{E})=10 \%$ purchase price (Hunt, 1977) and $\mathrm{L}_{\mathrm{m}}=$ Lifeexpectancy of the machine (10 years). Assumed that yearly operating days $=180$ days/year and daily operating hours of $8 \mathrm{~h}$.

Interest on investment; was estimated using the following equation:

$$
\mathrm{I}=\left(\mathrm{P}_{\mathrm{m}}+S\right) i / 2
$$

Where; $\mathrm{I}=$ Interest on investment (L.E./year) and $\mathrm{i}=$ Interest is compounded annually (rate/year).

Shelter, taxes, and insurance; were assumed $2 \%$ the machine purchase price.

Repair, maintenance, and lubricants; costs were assumed $100 \%$ of depreciation costs.

Electrical energy cost; Ec (L.E./h) = Electricity consumption $(\mathrm{kW})$ multiplying by electricity price (Assumed 1.5 L.E./kW.h).

Labor cost; is defined as payment for an operator who operates the machine (L.E./h). Labor wage (One laborer) $=10$ L.E/h.

Production cost; cost was calculated according to the following equation:

$$
\text { Production cost }(\text { L. E } / \mathbf{k g})=\frac{\text { Operation cost }(\mathrm{L} . \mathrm{E} / \mathrm{h})}{\text { Machine productivety }(\mathrm{kg} / \mathrm{h})} \ldots \ldots
$$

Statistical analysis; the results were statistically analyzed according to Gomez and Gomez (1984) using the computer MSTAT-C statistical analysis package by Freed et al. (1989). The least significant differences (LSD) test at probability level of 0.05 was manually calculated to compare the differences among means.

\section{Prototype feeding rate ( $\mathrm{Fr}, \mathrm{kg} / \mathrm{h})$.}

\section{RESULTS AND DISCUSSION}

Generally, results indicate a slight increase in the feeding rates with an increase in the linear speed of the conveyor belt. Figure (7) shows that the increasing the linear speed of the conveyor belt. The increase of feeding rates Nesma more than for Masa than 2020 cultivar is due to the difference in physical properties of each cultivar from the other, especially in value 
of average volume and mass of fruits, where the average mass of Nesma greater than Mass and followed 2020 cultivate with considering average time required to feed all fruits on the conveyor belt by the labor is almost constant for all three cultivar of tomatoes fruits.

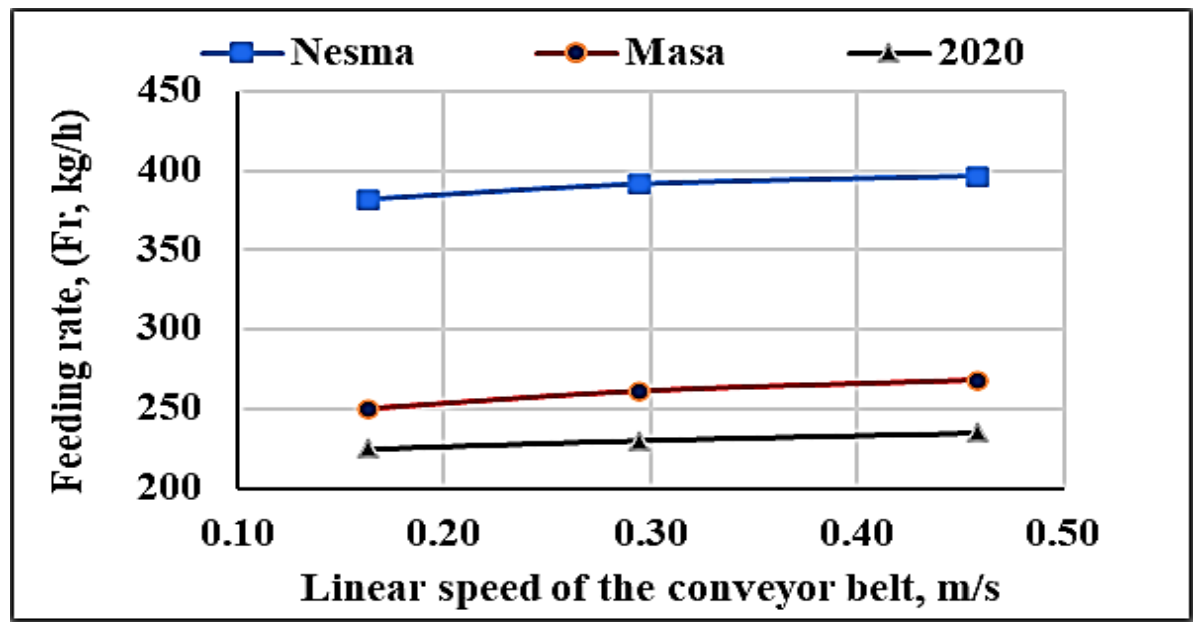

Figure (7): Conveyor belt speed via tomato Feeding rate

\section{Prototype productivity (P.m, kg/h)}

Figure (8) shows increasing the linear speed of the conveyor belt from $0.164,0.294$ to 0.458 $\mathrm{m} / \mathrm{s}$ for cultivars of Nesma, Masa, and 2020, respectively, leads to decrease average productivity of the fruits are dividing into two halves through the vertical axis.

The analysis of variance (LSD value at 0.05 ) indicated that the effect of cultivars and linear speed on productivity was significant, but it was non-significant for the effect of types of saw blades on productivity.

In addition, the triple interaction of the cultivars and the linear speeds of conveyor and types of blades has a significant effect on the productivity. The highest productivity was 370.24 $\mathrm{kg} / \mathrm{h}$ for Nesma cultivar at the lowest linear speed of conveyor with the straight saw blade.

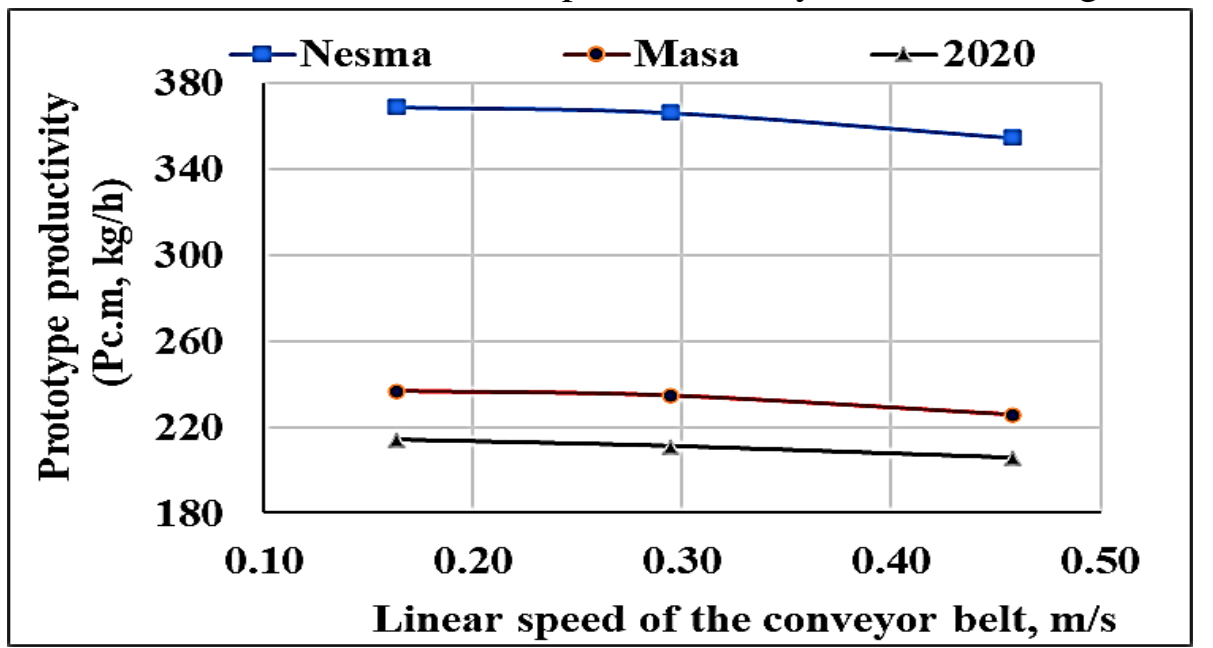

Figure (8): Prototype productivity as affecting by conveyor belt speed

\section{Percentage of damage $\left(D_{f}, \%\right)$}

The results showed that increasing the conveyor belt speed leads to increase of percentage of damage for cultivars of Nesma, Masa and 2020, respectively. Figure (9) shows the average damage percentage via increase in the conveyor belt linear speed. The analysis of variance 
(LSD value at 0.05 ) indicated that the effect of cultivars and linear speed on percentage of damage was significant. The lowest percentage of damage was 3.41 for cultivar of Nesma at lowest linear speed of conveyor, while highest percentage of damage was 15.27 for cultivar of Masa at highest linear speed of conveyor. In addition, was non-significant for the effect of types of saw blades on percentage of damage. Triple interaction of the cultivars and the linear speeds of conveyor and types of blades have non-significant effect on percentage of damage.

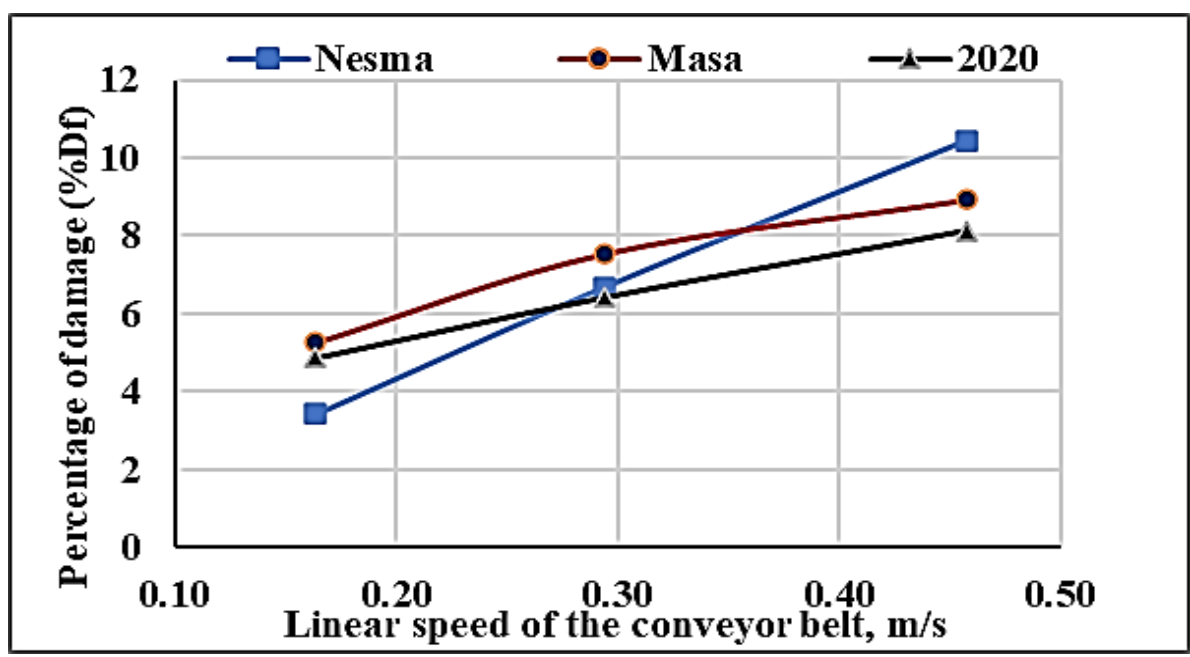

Figure (9): Average percentage of damage via conveyor belt speed

\section{Cutting efficiency $\left(\eta_{c}, \%\right)$}

The cutting efficiency is the most important determinant of choosing the appropriate linear speed conveyor belt. The cutting efficiency of the machine depends on the proportion of the fruits that have been dividing into two equal halves through the vertical axis without any damage. The fruits cut from their side or off-axis is considered damaged fruits. The results show that increasing the linear speed of the conveyor belt leads to a decrease in cutting efficiency while increasing the percentage of damage. From figure (10) increasing the linear speed of the conveyor belt from $0.164,0.294$ to $0.458 \mathrm{~m} / \mathrm{s}$ leads to decreasing of the cutting efficiency of the fruits Nesma, Masa and 2020 cultivars respectively. The highest efficiency of the fruit cutting process and the lowest damage is achieved by a linear speed of the conveyor belt $0.164 \mathrm{~m} / \mathrm{s}$ for cultivars of tomato fruits Nesma, Masa and 2020, respectively.

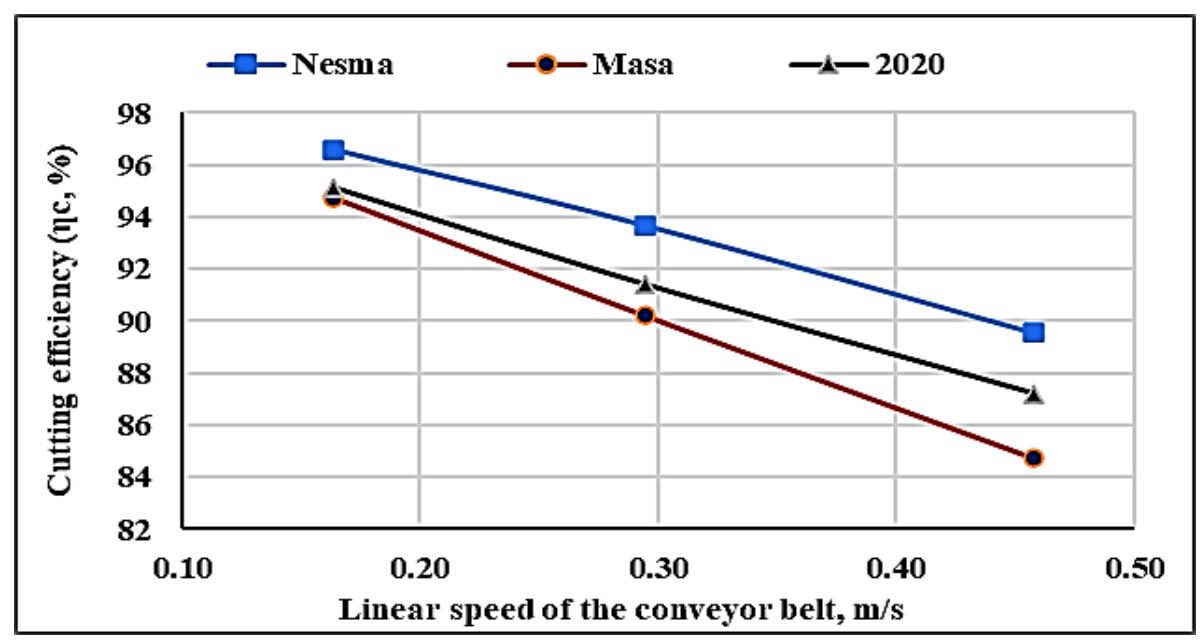

Figure (10): cutting efficiency via conveyor belt speed 


\section{Cutting quality}

By examining the fruits that were cut by three types of saw blade, was found that there no effect on the quality of the cutting surface for all fruits. Preferably using of smooth saw blade for low price. Figure (11) shows random samples of three tomato cultivars after cutting process by prototype.

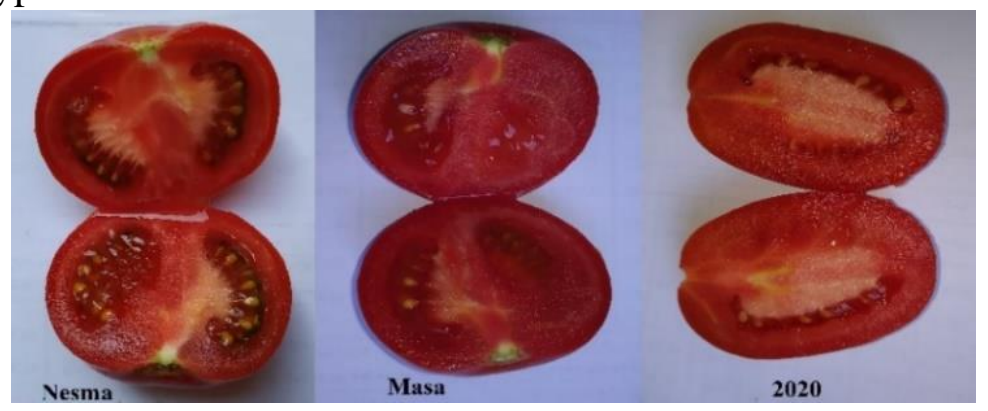

Figure (11): Random samples of three tomato cultivars after cutting process

\section{Cost estimation:}

Costs of operating the cutting tomatoes machine were estimated at the maximum value of the power required. Table (1) shows the costs of operating the cutting tomatoes machine. The results indicated that the total fixed costs were $0.661 \mathrm{~L} . \mathrm{E} / \mathrm{h}$, and the total variable costs were 15.931 L.E/h. So, the total costs for operating the machine will be $16.592 \mathrm{~L} . \mathrm{E} / \mathrm{h}$ under the same operating conditions.

Table 1: Costs of operating the cutting tomatoes machine

\begin{tabular}{|lll|}
\hline & \multicolumn{1}{c}{ Item, (L.E/year). } & Values \\
\hline \multirow{3}{*}{$\begin{array}{lll}\text { Fixed } \\
\text { costs. }\end{array}$} & Depreciation. & 450 \\
\cline { 2 - 3 } & Interest on investment. & 275 \\
\cline { 2 - 3 } & Shelter, taxes, and insurance. & 100 \\
\cline { 2 - 3 } & Total fixed costs. & 825 \\
\cline { 2 - 3 } $\begin{array}{l}\text { Variable } \\
\text { costs. }\end{array}$ & Retal fixed costs. & 0.661 \\
\cline { 2 - 3 } & Labor wage. & 0.361 \\
\cline { 2 - 3 } & Electrical energy cost. & 15 \\
\cline { 2 - 3 } & Total Variable costs. & 0.57 \\
\hline Total costs. & 15.931 \\
\hline
\end{tabular}

\section{Production cost:}

Production cost was calculated by the minimum values of prototype productivity 369.24 , 236.69 and $213.99 \mathrm{~kg} / \mathrm{h}$ for cultivars of tomato fruits Nesma, Masa, and 2020 respectively, it was obtained with the lower liner speed of the conveyor belt $0.164 \mathrm{~m} / \mathrm{s}$ for cultivars of tomato fruits Nesma, Masa, and 2020 respectively, which gave the highest cutting efficiency and lower the damaged percentage. Accordingly, the production cost will be 44.94, 76.71 and 77.54 L.E/Mg for cultivars of tomato fruits Nesma, Masa, and 2020, respectively. While the average productivity of a manual experienced labor was $195.55,130.86$, and $118.58 \mathrm{~kg} / \mathrm{h}$ for cultivars of tomato fruits Nesma, Masa, and 2020, respectively. Accordingly, the production cost will be 76.71, 114.63 and 126.50 L.E/ton for cultivars of tomato fruits Nesma, Masa, and 
2020 respectively. Also, the increases in production costs for cultivars of tomatoes fruits Nesma, Masa, and 2020, respectively, is due to the difference in the mass of the fruits of each cultivar from the other, while the feeding time is approximately constant for the numbers of fruits for all three cultivars of tomatoes.

Table (2) Figure (12) shows a comparison between the costs of manual cutting and cutting by using the developed machine at the productivity of the lower linear speed $(0.164 \mathrm{~m} / \mathrm{s})$ of the conveyor belt highest cutting efficiency for cultivars of tomato fruits Nesma, Masa, and 2020.

Table 2: Comparison between the costs of manual cutting and cutting by using the developed machine at linear speed $(0.164 \mathrm{~m} / \mathrm{s})$ of the conveyor belt

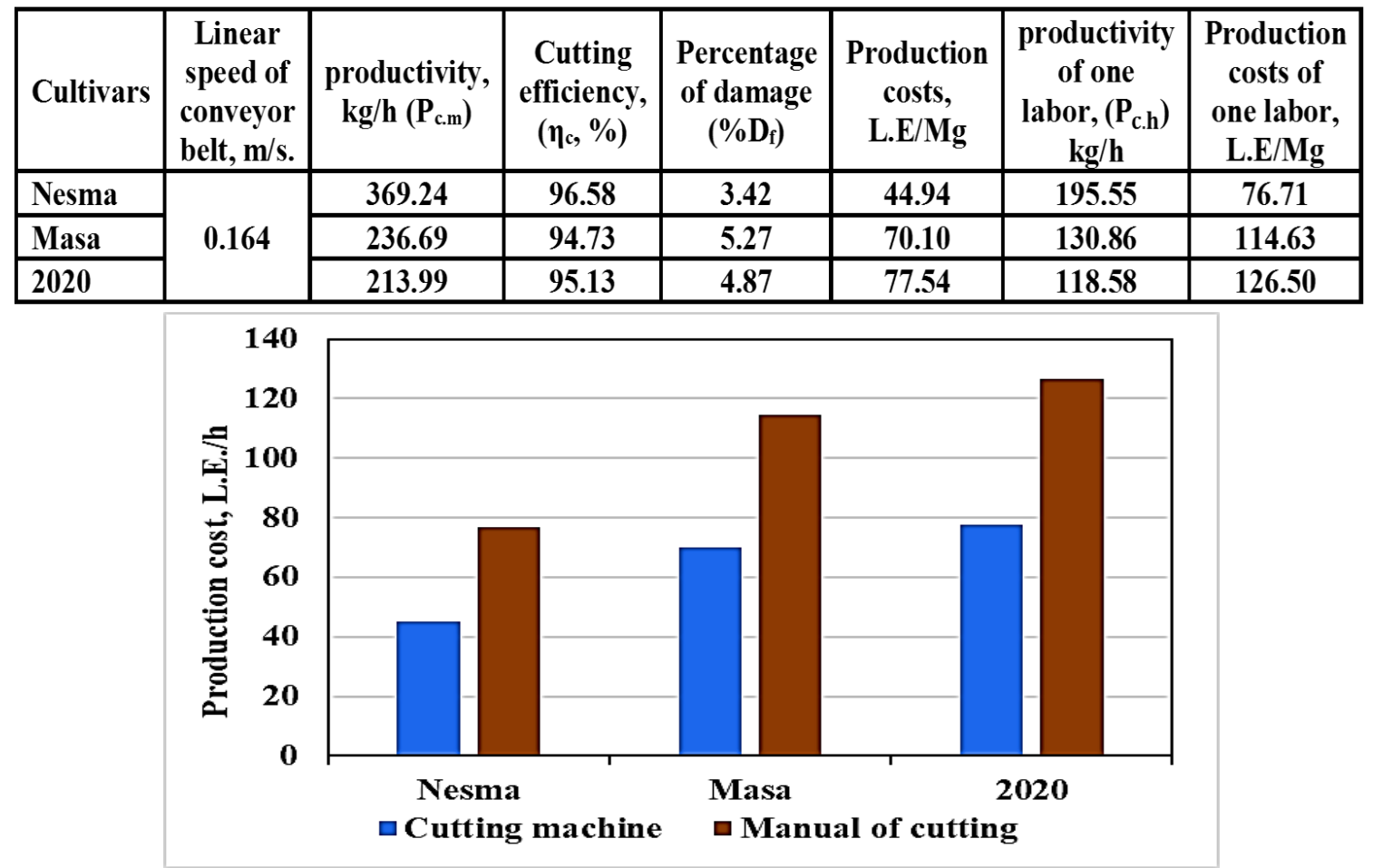

Figure (12): Comparison between production costs of manual and mechanical cutting via lower linear speed of conveyor belt

\section{CONCLUSION}

The developed prototype to cutting of the tomatoes fruits into two identical halves is simple to build and operate and therefore technically feasible and economically viable. Evaluation of performance of the prototype in cutting tomatoes into identical halves for the purpose of natural sun drying by used some cultivars (Nesma, Massa and 2020). The Primary performance results of prototype indicated to high productivity with high efficiency and low of costs production compared with manual cutting. It is recommended in future studies to develop this prototype for cutting tomato fruits to achieve on to operate mechanically sorting, washing for the tomato fruits.

\section{REFERENCES}

Agbetoye, L. A., and Balogun, A. (2009). Design and Performance Evaluation of a MultiCrop Slicing Machine. Proceedings of the 5th CIGR Section VI International Symposium on Food Processing, Monitoring Technology in Bioprocesses and Food Quality Management, Potsdam, Germany. 
Ananth, K. N. S., Rakesh, V., and Visweswarao, P. K. (2013). Design and selecting the proper conveyor-belt. International Journal of Advanced Engineering Technology, 4(2): 43-49.

Bahaa Ismail. (2020). Guide to the production of sun-dried tomatoes. Food and Agriculture Organization of the United Nations. Cairo. Available at: <https://drive.google.com/file/d/1Khz7yaRQIvT8PfUX7vH16ta4IGzPns-0/edit? fbclid=IwAR35Y7I0zNJTvE1YFSavhAltFUdQvH6tF5VcSOc8Puf7u4gPgVCyu9NHou0>

FAO. (2020). World Food and Agriculture - Statistical Yearbook 2020. Available at: <http://www.fao.org/faostat/ar/\#rankings/commodities_by_country $>$

Freed, R.S.P.; S.P. Eisensmith; S. Goetez; D. Reicosky; V.W. Smail and P. Wolberge (1989). Users guide to MSTAT-C.A software program for the design, moorage regiment and analyses of agronomic research experiments Michigan State University, U.S.A.

Gomez, K. A. and A. A. Gomez (1984). Statistical procedures for Agricultural Research $2^{\text {nd }}$ ed. John Wiley and Sons, Inc. New York.

Hoeberichts, F. A., Van Der Plas, L. H., and Woltering, E. J. (2002). Ethylene perception is required for the expression of tomato ripening-related genes and associated physiological changes even at advanced stages of ripening. Postharvest Biology and Technology, 26(2): 125-133.

Kamaldeen O. S, Arowora K.A, Abioye J. S. and Awagu E. F., (2016). Modification of Manually Operated Tomato Slicing Machine. International Journal of Engineering Science and Computing. 6 (7): 1983-1938.

Kamaldeen O. S. and Awagu E. F., (2013). Design and development of a tomato manual slicing machine. International Journal of Engineering and Technology. 2 (1): 57-62.

Mahmoud, W. A., Mahmoud, R. K. and Eissa, A. S. (N. d.). Determining of some physical and mechanical properties for designing tomato fruits cutting machine. Agricultural Engineering International. CIGR Journal. Accepted submission and in preparation.

Ozumba, I. C., Ademade C. A., Jackson, B. A., and Adejumo O. A., (2004). Testing of National Centre for Agricultural Mechanization Treadle Cassava Grater. The 5th International Conference and 28th Annual general meeting of the Nigerian Institution of Agricultural Engineers, 26: $63-67$.

Raji, O. A. and Igbeka, J. C. (1994). Pedal Operated Chipping and Slicing Machine for Tuber. Journal of Agricultural and Engineering Technology. 2: 90-99.

Shittu S. K., Bello M., and Dangora N. D. (2017) development of a motorized tomato (Solanumlycopersicum L.) slicer. Arid Zone Journal of Engineering, Technology and Environment, 13(2):197-208.

Taheri-Garavand, A., Ahmadi, H. and Gharibzahedi, S. M. T. (2009). Investigation of moisture-dependent physical and chemical properties of red lentil cultivated in Iran. In International Agricultural Engineering Conference (IAEC). Bangkok, Thailand: 7-10. 
تصنيع آلة شطر ثمار الطماطم لعملية التجفيف الشمسي

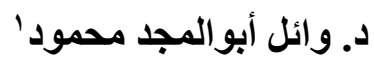

' مدرس ـ كلية الهندسة الزراعية - جامعة الأزهر فرع أسيوط ـ مصر.

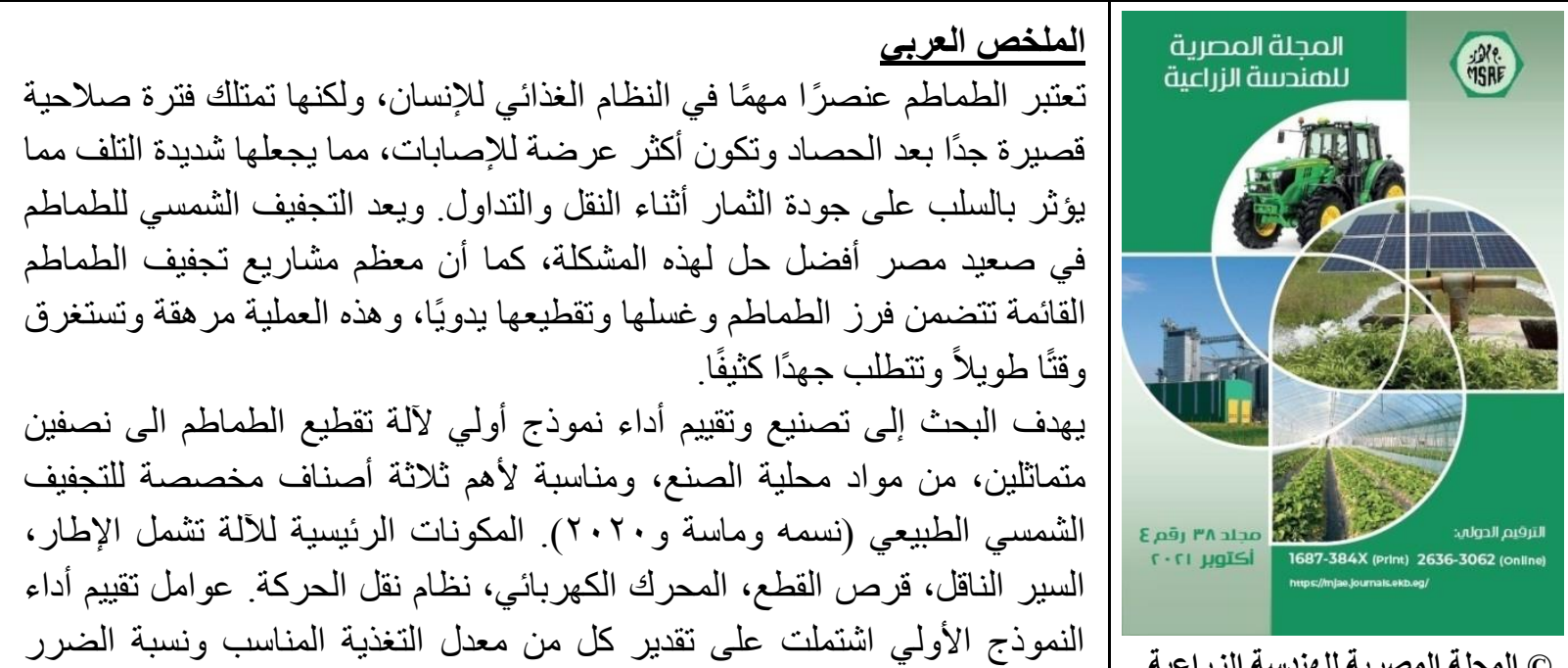

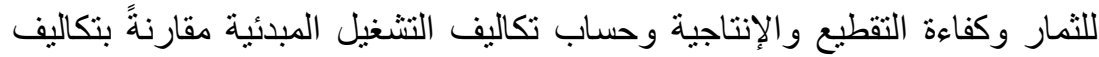

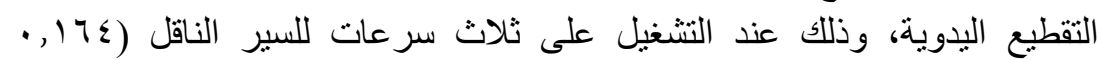

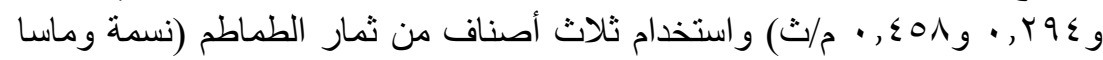

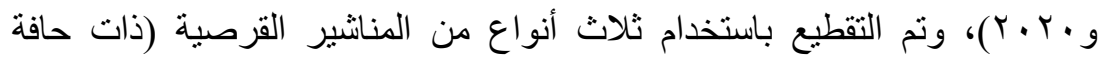

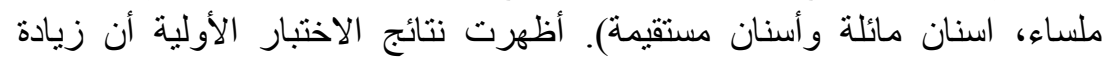

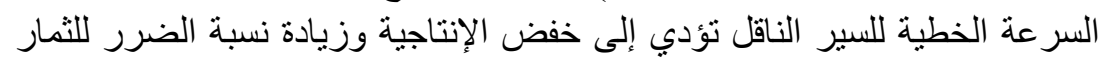

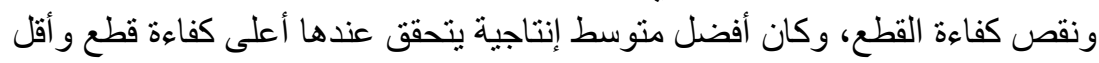

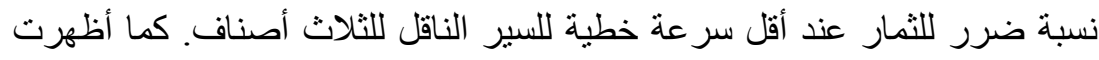

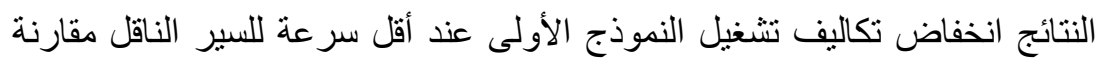
بالتقطيع اليدوي. التوصيات؛ يوصى بتطوير هذا النموذج الأولي بحيث يعمل على تنظيف وتتشيف وتدريج الثمار قبل تقطيعها.
C) المجلة المصرية للهندسة الزراعية

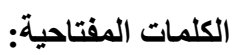

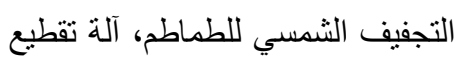
الطماطم، انتاجية الآلة، كفاءة التقطع التطع 